$\mathbb{P}$ periodica polytechnica

Social and Management Sciences $21 / 1$ (2013) 21 26

doi: $10.3311 /$ PPso. 2153

http://periodicapolytechnica.org/so

Creative Commons Attribution (1)

RESEARCH ARTICLE

\section{Analyzing and forecasting global business markets: Reflections and recommendations}

\author{
Andrew C. Gross
}

Received 2013-01-10

\begin{abstract}
My goal in this article is to distill some key ideas I have learned over 50 years of analyzing and forecasting global markets that should be useful to academics as well as practitioners. The discussion moves from the general to the specific and back, offers illustrations, and concludes with a few lessons and guidelines. Part 1 shows why a two-fold view of categorization is far too narrow in a complex world. Part 2 demonstrates that both academics and practitioners face three underlying challenges, namely topic choice, budgeting and procedure; then Part 3 reveals how to tackle these and related issues. In Part 4 the discussion traces the expanding scope of global market research and the key challenge of building consistent market analysis and forecasts in an age of information overload. Part 5 shows illustrative case studies drawn from books and monographs. Finally, Part 6 offers lessons and guidelines. A bibliography and a short biography are provided.
\end{abstract}

\section{Keywords}

business-to-business marketing $\cdot$ global market research . product and market analysis - forecasting - career-building . academics and practitioners

\section{Acknowledgement}

Parts of this paper were published first in the Research Newsletter of the Institute for the Study of Business Markets, 5/2, August, 2012; reproduced here by permission.

\section{Andrew C. Gross}

Department of Marketing, Cleveland State University, 2121 Euclid Avenue, BU 460, Cleveland, OH 44115-2214

e-mail: a.gross@csuohio.edu

\section{Beyond a two-fold view}

We like to classify things into two categories. Dual, dyadic and dichotomous views are across the landscape as in: art vs. science; theory vs. practice; objective vs. subjective; domestic vs. foreign; macro vs. micro; and so forth. In global business we speak of: strategy vs. tactics; competition vs. collaboration; emerging vs. mature markets; fragmented vs. concentrated industries; and high-tech vs. low-tech sectors. In marketing we see the same pattern: product vs. service; consumer vs. industrial goods; skim vs. penetration pricing; and, transactions vs. relationships. Then, in analyzing and forecasting, we often refer to: short vs. long run; qualitative vs. quantitative techniques; cross-section vs. longitudinal surveys; information gaps vs. information overload; and, primary vs. secondary data sources.

Yet the most interesting aspects are often in the "big middle" and worthy of examination. Thus, in global marketing there are contractual arrangements of many kinds between the two polar opposites of foreign trade and direct investment. We now recognize many offerings that are truly half tangible product and half service. In market segmentation, we have several intermediate bases between macro and micro bases. In projecting the size of markets, we have embraced composite (or consensus or combination) forecasts that combine "qual" and "quant" with a good track record. Finally, in much of the academic and the business world, we have come to accept mixing art and science; we can even speak of this mix as enlightened craftsmanship, the designing and the shaping of our world in a blended mode.

Over the past half century I tried to follow this middle path, blending primary and secondary research on regional and global markets in a variety of ways. Let me sketch in the challenges and problems one is likely to face, illustrate with examples and then offer a few insights. My motto here was and is: "data detective on a prowl." As my career has blended theory and practice, the lessons are mixed as well-some are for academics writing for peer-reviewed journals and some for practitioners with needs to analyze/forecast markets beyond domestic ones. If you can, if you dare, combine the two streams for "real progress" [21]. 


\section{Key challenges and issues}

The first challenge in doing market research beyond the domestic scene is a matter of resource allocation. You need to make the commitment in terms of effort and your budget, whether you are an academic or a practitioner, whether you are flying solo or belong to a team. You must choose between primary interviews vs. published sources, then between doing it in-house and outsourcing. While even graduate students and small entrepreneurs have been known to engage research agencies abroad, it is best to start -whether academic or practitionerwith the wealth of widely available data off and online and then forge ahead. But keep the scope narrow, focus on certain sectors, aim at select market segments.

The second challenge facing both types of researchers is the decision on the specific topic(s) of interest. For many years, in our academic field, two "hot buttons" were industrial buying behavior and sales force management. In other words, how does relationship marketing unfold in such circumstances? For practitioners working with vendors of goods and services, the most relevant subject has been the product-market interface. What shall be offered and to whom-to which end-users, how, and at which locations? Given our interconnected world, the answer was to move outside the domestic scene, at a measured pace, offering well-defined specific services and, as already noted, targeting select clients. In all these cases, there is much to be said for the idea of relationship marketing, a grand topic that is likely to unite business marketing academics and practitioners for years to come.

The third challenge is two-pronged: Is market research necessary to forecast the size and judge the nature of the marketplace, can it be omitted, or cut short?! If it is needed, how and where do we find the requisite information?! Just "born global" software service firms expand rapidly and find many users around the globe. Have they done much market research? It is unlikely; it is doubtful. On the other hand, the vendors of machine tools, mining machinery, water treatment chemicals, security services, or management consultancies are more studious in their market research. They use internal data first; consult with associations, and other agencies; and tap many external databases. Next they turn to multi-client, off-shelf studies for market estimates nation by nation. Finally, if there are still gaps in their information, a limited journey of primary research is a great idea, using a cost-benefit scenario. This sequence, I hold, applies to both academics and practitioners. In sum, given the three challenges, all researchers have to decide on: budget, topic, and procedure.

\section{From buying behavior to market forecasts}

In the mid-1970s, a graduate student, with much business experience and ambition, wanted to do a "big survey" with me on "how industry buys" in the paper and chemical industries. Together, we found that this type of survey was done earlier in 1967 in the UK and in 1969 in the USA. We chose to replicate the survey done by Scientific American, Inc. for compar- ison and contrast. (SAI commissioned the original survey to show that its readers were key influencers on the purchase of industrial goods.) Our results confirmed previous findings as to buying behavior and purchasing patterns. Then I recruited colleagues in Australia, Canada, and UK to conduct the same survey in the two key industries (paper and chemicals) and on the same product categories (equipment, materials, and components). Eventually, we expanded the survey to France, Hungary, and even beyond. Our key finding was that the role played by various influencers on the procurement process was highly similar across nations and over time, with some minor exceptions e.g. the slightly greater role of engineers in Western Europe. This was a significant result, indeed, showing stability over time in different national settings.

The sequence outlined above lead to three key lessons. First, it was possible to do regional research on a limited budget via replication and with volunteer academics. Second, respondents expressed a strong interest beyond the purchasing patterns, asking for further market analysis that would assist them to judge the size and nature of foreign marketplaces. Third, cooperation with colleagues across borders yielded publishable findings in the academic literature. Based on this, I dedicated myself to similar work, in a collaborative stance with both academics and practitioners, and also rejoined a firm that I helped establish back in 1960. This was Predicasts, Inc., a pioneer in the business information industry, with its lineup of compressed data and early industry studies. Today there are hundreds of such vendors -see marketresearch.com- but back in the 1960s and early 1970s it was just a handful of pioneering firms that offered in-depth industry and market reports.

\section{From information vending machine to knowledge café}

Compressing quantity, upgrading quality.- While published forecasts were plentiful even back in 1960, they were not organized. The solution was to compress each forecast to a single line, using standard industrial classification code. Hence, users were able to judge changes, through comparison of growth rates of products and markets. Further, it was now possible to fill gaps in historical, current, and projected figures by looking not just at the time series for particular product in question, but also at its components and aggregates. What this means is that in a hierarchical scheme (as in the old SIC or the new NAICS system), statistics about a 4-digit product are inferred by knowing the adjacent 3-digit and 5-digit categories. In a similar fashion, data gaps for a given nation is overcome by inter or extrapolation, utilizing the statistics reported for economies at the same stage of development.

But market researchers want insights and analysis beyond one-line statistics about the past and the future; this resulted in a the creation of different kinds of abstracts, digests, and indexes such as Chemical Abstracts, Predi-Briefs, FES Index of Corporations and Industries, usually on a sector by sector and 
a country by country basis. These in turn spawned in-depth, multi-client U.S. and world studies by firms such as Creative Strategies, Frost \& Sullivan, Predicasts, and many others. Their reports, varying in length, depth, and quality offered overviews of product lines, market characteristics, and industry structure, plus profiles of leading firms. Users want reports on a consistent platform of economic and market indicators, that is a framework with internally reliable and valid way of viewing the product/market interface in question. Such practice continues to this day among "quality vendors" of such reports. Who are the highly rated vendors? Look at their longevity and their growth as well as the demand for revised editions of previous studies.

Data, accuracy, politics.- During 1950-1975 one could find discrepancies of $10 \%$ to $20 \%$-or even higher- for the same production figures among authoritative government and wellcrafted private sector reports. In a pioneering treatise, Oskar Morgenstern insisted: "economics is a one or two-digit science." However, by 1991, the "Good Statistics Guide" of The Economist, citing several criteria, claimed that Western nations, lead by Australia, Canada, Netherlands, Sweden, had significantly improved their official data. But statistical bureaus still have diverse policies on surveys and different industrial classification schemes. It is evident too that many for-profit data publishers focus on areas where high growth rates can be exhibited.

Forecasts and Track Records.- During 1975-2000 industry/market studies proliferated along with forecasts. At Predicasts we thought it would be appropriate to take a look back at our track record; we did so and found mixed results. Ten-year forecasts for USA (five economic, five major industry) made in 1960 for 1970 had a median discrepancy of only $2.7 \%$, a remarkably low figure; this was truly an era of economic stability. On the other hand, in the 1970s, the forecasts on plastics output and usage for Germany were $30 \%$ off the mark due to the rise in oil prices for OPEC. In high-tech (not a Predicasts specialty), discrepancies were much higher. Thus, in the case of small disk drives, created via disruptive technology in 1980s, errors of $35 \%$ to $550 \%$ prevailed four years ahead (see Christiansen's famous book on this) [3]; for further details, see our lengthy evaluation of the field [12]. The key question then becomes: Can we do better in forecasting?!

Improvements and Insights. - The short, but imprecise answer to the question just posed is: "not too likely, but..." In the past three decades, there has been an explosion in available information with more sources, forecasts, and interpreters. In the 1980s, number of databases and online services increased more than tenfold. In the 1990s search techniques were refined greatly via use of keywords and other Boolean techniques. In the 2000s firms accelerated their move to tap their own databank ("if only HP knew what HP knows"). They intensified their search for feedback from lead users and beta sites; foreign listening posts came in vogue. Academics now collaborate across borders via e-mail, conference calls, Skype, etc. All of this activity, however, does not mean better forecasts; some centers on the topic still flourish (Georgia State), but others have closed (Southern California).

Staff people at market research firms, including Predicasts and its successor The Freedonia Group, improved their forecast 'game' in several ways: doing more primary research via interviews; using the build-up and break-down method in tandem; mining deeper in databases; and using the purchasing power parity scheme of the World Bank for a consistent comparison. For details, see my article on global water pollution control markets in European Journal of Marketing [9], and many other, coauthored ones, during past two decades, in Business Economics.

Improvements on the forecasting front have to be accompanied by much more analysis and specific insights; readers want more than the "global total." Today, in-depth reports show how national markets differ, how the product line is adopted, and whether the industry in question is fragmented or concentrated. Indeed, analysis is as crucial as provision of projections. For example, how do chemicals compete against equipment in wastewater treatment as users make a decision between operating and capital expense? Within chemicals, how do costly, but highly effective organic compounds compete against cheaper, but less effective inorganic compounds $[8-[10]$ ? Which areas are growing and which are declining in management consultancy and why [13]?

Content(s) and Discontent(s). - In media, content is king as it should be; in market research, the same is true. But how does one "sift and winnow" the wheat from the chaff? Answer: combine art and science, more specifically experience and rule(s) of thumb. Every one has his or her favorite database. Dissertation Abstracts is one of my favorites because it has great abstracts on obscure topics. High price reports from associations and for profit publishers may or may not be worth the fee. My co-author and I found some problems on market size estimates for management consultancies, both worldwide and in the UK, in reports by private sector publishers and associations. Each entity had its own definition; further, they often broadened the scope of the field to show more robust growth rates [13].

In my current sabbatical research, I am looking at engineering consultancies in major industrialized nations first, and later on in emerging markets. In this heroic, (possibly quixotic?!) quest I visited the U.S. Census Bureau, Statistics Canada, Australian Bureau of Statistics, and their equivalent in Hungary and New Zealand, seeking official data on revenues, employees, and foreign trade. At the same time, contacted national and global associations as well as knowledgeable individuals. My primary goal is to gain insights on the state of the sector and my secondary goal is to resolve conflicts among data sources. Only then will I dare to go out on a limb by considering the art and science of looking ahead and making projections. What I found so far is that looking at service sector data is far more complex than counting agricultural commodities, construction completions, and manufactured goods.

In the next section three illustrations are offered based on ex- 
tensive research conducted during the past decade in different areas. In each case the research was carried out on a global basis over several months and based on a broad combination of primary and secondary sources, including interviews with experts in the field, contacts with trade and industry associations, tapping the databases of national statistical bureaus and international agencies as well as many books and journals.

\section{Three illustrative global studies}

Mining Machinery.- During 2001-2006 there was a sharp "run-up" in the prices of many natural resources due to demand from fast-growing economies such as China and India. This prompted renewal in mine exploration and development around the globe and, in turn, resulted in a positive impact on demand for mining machinery. The central question facing the author of a major monograph on this topic, Michael Deneen of The Freedonia Group, was whether or not this trend could be sustained during 2006-2011. The answer came in as a clear "no" due to several factors: slowdown in consumption; depletion of resources; ecological pressure to reuse, recycle, and conserve; and, concern with safety in all mining activities.

In an article, based on the monograph, we discuss this situation and show that growth rates in mining activities and shipments of mining machinery would slow down. Compared to 2001-2006 we saw the following decline in rates for 2006-2011: for minerals, from $5.8 \%$ to $4.2 \%$; for coal, from $5.8 \%$ to $2.4 \%$; and for metals, from $7.9 \%$ to $4.8 \%$. The impact on mining machinery, in the two periods cited, would be a similar major slowdown in their annual growth rates: mineral mining equipment declining from $7.8 \%$ to $5.1 \%$, coal mining units from $12.1 \%$ to $5.5 \%$, and metal mining equipment from $10.4 \%$ to $6.9 \%$ [5].

Four distinct regional patterns emerged in analyzing the demand for and supply of mining machinery. Many mid-size emerging nations in Africa, Asia-Pacific, and South America rely on natural resource extraction in general and mining in particular. Thus, they comprise a growing market for equipment; but as yet they do not have the capability for producing sophisticated equipment. The second group consists of the industrialized nations of Western Europe, Japan, South Korea, and Taiwan. These countries have limited mining activity, but they produce high-caliber equipment, much of it exported. The third group encompasses Australia, Canada, South Africa, and USA - they have significant mining activities and produce advanced equipment for domestic and foreign clients. Countries in the fourth group, Brazil, China, and Russia, boast large mineral, coal, and metal resources but it will take a decade until they join the third group in making advanced units.

Mining machinery manufacturers emphasize pre and postsales service at home and abroad. Of the $\$ 33.6$ billion worth of global shipments in 2011, about 50\% is in foreign trade. Many large firms engage in wholesale financing for dealers and retail financing for specific customers. They also have a strong service network to offer parts and accessories. Promotion is via trade shows, direct mail, seminars, advertising online and in trade journals, but personal selling still prevails with large customers. Pricing is competitive globally, especially for standard items. Product development is ongoing with emphasis on safety features and robotics. The industry has hundreds of companies, but there is specialization. A total of six firms account for about one-fourth of the global market: Atlas Copco and Sandvik of Sweden; Bucyrus International, Joy Global, Terex from USA; and, Metso of Japan.

Management Consulting.- This field is of much younger vintage than either management practice or management theory. Today, it is a high-pressure, high-level practice, but it is also striving hard to be viewed as a profession. The locus of this attitude or 'positioning' is the firm itself in the case of large consultancies and the individual in the case of small ones. In the latter situation, emphasis is put on certification after gaining experience and passing examinations. The origins of the field can be traced to England in the second half of the $19^{\text {th }}$ century with accounting firms offering what was then called 'advisory practice.' The flowering of the field came of age in USA between two world wars and then in Europe as well. Emerging trends are accountability and transparency, with clients expecting not just expertise, but implementation. Observers now estimate global volume around $\$ 300$ billion.

This author's involvement in the field can be traced back to partnering with a Hungarian expert, Dr. Jozsef Poor, currently a professor at Szent Istvan University, formerly at the University of Pecs, and former managing director of Hay Group and Mercer HR in Budapest. Our co-authored book on management consultancy in Eastern Europe was published by KJK in Hungary in 2003. Subsequently, we focused on the European and global scene, including recent annual reports for FEACO, the federation for consultancy associations in the EU, and then a major article analyzing worldwide trends [13]. In our publications, we emphasized that the underlying statistics in the field are controversial in part due to lack of solid national statistics from many nations and in part publishers inflating the size of the sector in order to demonstrate healthy growth rates. We recommend checking and contrasting several sources, along with building composite or consensus forecasts.

The major service lines offered by management consultants worldwide have been traditionally classified into four groups: strategy, human resources, operations, and information technology. The first two were emphasized before the 1990s; since then, the last two became dominant with IT taking almost $30 \%$ of the total. The major clients for services come from the ranks of manufacturers, natural resource firms, banks and other financial entities, and national governments. Of the 50 leading vendors about 40 came from the USA, the rest from EU and Japan in 2008. But the situation is changing with faster growth in emerging markets where private and public entities will likely favor domestic or regional consultancies.

Indeed, we can see already that Infosys, Tata Consulting, and 
Wipro from India and other large firms from China, Brazil, and elsewhere are making inroads on the market shares now held by such U.S. firms as Accenture, Bain, BCG, CSC, EDS, IBM, McKinsey, Monitor, Mercer and European firms such as PA and Roland Berger. The four largest accounting firms from the USA have resumed offering consultancy services and this will also have a worldwide impact. The competitive battle will be fought on a client-by-client basis on the market side and in the hiring of top talent. We expect additional mergers and acquisitions as well as alliances and partnerships. Small consultants can still prosper by marketing and entrepreneurial orientation; they must be proactive, innovative, and risk-taking. For all of the participants we see the challenge as tailor-made offerings at a competitive fee; the era of so-called 'boiler-plate' or identical solutions to several clients at high hourly rates is over.

Security Equipment and Services.- This fast-growing sector consists of a mix of alarm monitoring, cash-in-transit (armored car, automated teller machine) and integrated system services along with stationary and mobile guards on property patrol. The sector gained prominence as individuals and nations achieve higher income levels and wish to protect themselves and their property from intruders. Other factors promoting growth are increase in real or perceived crime, cutbacks in police forces, and publicity about crime in the print and electronic media. Many observers trace the roots to a deeper level, focusing on rapid urbanization and high rates of youth unemployment. The global revenue of the sector is now estimated at $\$ 185$ billion, with a growth rate at $7.4 \%$ per annum through 2019 [16].

Contract guarding will continue to be the largest segment of the market with more than half of total revenues in 2014 as labor costs are quite low and regulation is not too onerous. However, strongest growth prospects are for systems integration and consulting plus alarm monitoring due to capital investments and the transition to electronic security options. Commercial and industrial establishments account for $71 \%$ of the client base, governments and public institutions for $16 \%$ and residential users for the remaining $13 \%$ of the total. This mix of clientele is invariably local in character and there is no foreign trade in security services. Furthermore, most firms are still small and independently owned. However, the major vendors have become increasingly international in scope and they are acquiring smaller firms. Globally, the leaders are Brink's (USA), Tyco (Switzerland), Securitas (Sweden), G4S (UK), Prosegur (Spain), and Secom (Japan); they hold about $21 \%$ of the global market.

In developing this massive 500-page monograph, the analyst relied on a wide variety of primary and secondary sources including statistical bureaus, criminal justice organizations, and foreign embassies. She also consulted the databanks of Eurostat, OECD, UN, World Bank, IMF, and Interpol. Numerous industry and trade associations were contacted in Australia, Canada, EU, India, Latin America, et al. Finally, brokerage reports, trade journals, and the annual reports and the product catalogs of the leading companies were utilized.

\section{Lessons learned, suggestions offered}

My remarks here are aimed at both academics and practitioners. A young professor should consider joining a start-up firm and/or taking on consultancy or internships. A senior manager should share his insights and give guest lectures; possibly later join academe, after easing (eased?!) out of industry. The mix of the two worlds has been a challenging, but a satisfying journey for me over the years.

1 Start by standing on the shoulders of those who did good work before you. There are numerous surveys that can be replicated, emulated, then updated, expanded; doing this can result in useful, publishable "semi-longitudinal" studies.

2 While respecting existing streams of research and doing the replication, strive also to go out on a limb, create your own niche, and embark on some form of pioneering venturepreferably with other, like-minded colleagues, near or far.

3 Establish a specific product/market interface for your focus in the framework of a well-defined industry sector. Then, expand your horizon and go into adjacent areas; later on, consider entering entirely new fields.

4 Always compare and contrast. Through such means you can "winnow and sift," draw out the key similarities and differences. In doing so, listen to the numbers, but do not torture them to fit your or others' pre-existing concept.

5 Forecast with care, adopt the idea of crowd-sourcing or the wisdom of experts; believe no-one, consider every-one. Welcome information overload, but then quickly reduce quantity, upgrade quality. Offer analysis, not just forecasts.

6 Always go global or at least regional. The domestic base is useful, but in the 21 st century, the world can be your marketplace. Start with a few key countries and immerse yourself in their ways, if possible via lengthy visiting assignments.

\section{References}

1 Armstrong JS, Principles of Forecasting, Wiley-Blackwel; New York, 2001.

2 Banting P, Ford D, Gross A, Holmes G, Similarities in Industrial ProProcurement Across Four Countries, Industrial Marketing Management, (1985, May), 133-144.

3 Christiansen C, The Innovators's Dilemma, HBS; Boston, 1997, pp. 148150.

4 Craig S, Douglas S, International Marketing Research, 3rd edn., Wiley; Sussex, 2005.

5 Deneen M, Gross A, World Mining Machinery, Business Economics, 44(3), (2009), 169-176, DOI 10.1057/be.2009.2. This article is based on M. Deneen, World Mining Machinery, Cleveland: The Freedonia Group, 2008. It is a 340 pp. monograph.

6 Duncan J, Gross A, Statistics for the $21^{\text {st }}$ Century, Irwin; Chicago, 1995.

7 Erickson R, Gross A, Generalizing Industrial Buying: A Longitudinal Study, Industrial Marketing Management, (1980, July), 253-265.

8 Gross A, Water Management Chemicals, 2 vols., Predicasts; Cleveland, 1984. $4^{\text {th }}$ ed. 
9 Gross A, Global Competition for Environmental Markets, European Journal of Marketing, 20(2), (1986), 22-34. This article is based on World Water Pollution Control Equipment, a long monograph published in 1980 by Predicasts, Inc. Other scholarly artecles based on this volume appeared in refereed environmental, management, marketing and law journals.

10 Gross A, The Information Vending Machine, Business Horizons, (1988, January-February), 24-36.

11 Gross A, Banting P, Meredith L, Ford D, Business Marketing, Houghton Mifflin; Boston, 1993.

12 Gross A, Joseph B, Analyzing and Forecasting World Markets-[Reprise], ESOMAR; Amsterdam, 1997, pp. 583-608.

13 Gross A, Poor J, The Global Management Consulting Sector, Business Economics, 43(4), (2008), 59-68, DOI 10.2145/20080408.

14 Hutt MD, Speh T, Business Marketing Management, Cengage/SW; Mason, $\mathrm{OH}, 2013$. See p. 115 quoting various authors on composite forecasting.

15 Kuada J, International Market Analysis, Adonis-Abbey; London, 2008.

16 Mapes JL, World Security Services, The Freedonia Group; Cleveland, 2011. This is a 500 pp. monograph.

17 McNees S, The Uses and Abuses of 'Consensus' Forecasts, Journal of Forecasting, December, (1992), 703-710.

18 Morgenstern $\mathbf{0}$, On the Accuracy of Economic Observations, Princeton University Press; Princeton, 1963.

19 The Economist, Vol. 65, 1993, 11 Sep.

20 Poor J, Gross A, Management Consultancy in an Eastern European Context, KJK-Kerszov; Budapest, 2003.

21 Reibstein D, Day G, Wind J, Guest Editorial: Is Marketing Academia Losing Its Way?, Journal of Marketing, 73(4), (2009, July), 1-3, DOI 10.1509/jmkg.73.4.1.

22 Schnaars S, Megamistakes, The Free Press; New York, 1999.

23 Surowiecki J, The Wisdom of Crowds, Anchor Books; New York, 2004. 